\title{
International comparison of the German evidence-based S3- guidelines on the diagnosis and multimodal treatment of early and locally advanced gastric cancer, including adenocarcinoma of the lower esophagus
}

\author{
Markus Moehler • Christoph T. H. Baltin • Matthias Ebert • Wolfgang Fischbach • Ines Gockel • \\ Lars Grenacher • Arnulf H. Hölscher • Florian Lordick • Peter Malfertheiner • Helmut Messmann • \\ Hans-Joachim Meyer • Anne Palmqvist • Christoph Röcken • Christoph Schuhmacher • Michael Stahl • \\ Martin Stuschke · Michael Vieth • Christian Wittekind • Dorothea Wagner • Stefan P. Mönig
}

Received: 7 October 2013/Accepted: 13 July 2014/Published online: 7 September 2014

(C) The International Gastric Cancer Association and The Japanese Gastric Cancer Association 2014

\begin{abstract}
Background Clinical guidelines are essential in implementing and maintaining nationwide stage-specific diagnostic and therapeutic standards. In 2011, the first German expert consensus guideline defined the evidence for diagnosis and treatment of early and locally advanced esophagogastric cancers. Here, we compare this guideline with other national guidelines as well as current literature.
\end{abstract}

M. Moehler and C.T.H. Baltin contributed equally.

Electronic supplementary material The online version of this article (doi:10.1007/s10120-014-0403-x) contains supplementary material, which is available to authorized users.

M. Moehler · I. Gockel · A. Palmqvist

University Medical Center Mainz, Mainz, Germany

M. Moehler $(\bowtie)$

Medizinische Klinik und Poliklinik, Johannes-Gutenberg-

Universität, Langenbeckstraße, 155101 Mainz, Germany

e-mail: markus.moehler@unimedizin-mainz.de

C. T. H. Baltin · A. H. Hölscher · S. P. Mönig

University Hospital of Cologne, Cologne, Germany

M. Ebert

University Medical Center Mannheim, Mannheim, Germany

W. Fischbach

Klinikum Aschaffenburg, Aschaffenburg, Germany

L. Grenacher

Heidelberg University Hospital, Heidelberg, Germany

F. Lordick

Klinikum Braunschweig, Braunschweig, Germany
Methods The German S3-guideline used an approved development process with de novo literature research, international guideline adaptation, or good clinical practice. Other recent evidence-based national guidelines and current references were compared with German recommendations.

Results In the German S3 and other Western guidelines, adenocarcinomas of the esophagogastric junction (AEG) are classified according to formerly defined AEG I-III subgroups due to the high surgical impact. To stage local disease, computed tomography of the chest and abdomen and endosonography are reinforced. In contrast, laparoscopy is optional for staging. Mucosal cancers (T1a) should be endoscopically resected "en-bloc" to allow complete histological evaluation of lateral and basal margins. For

P. Malfertheiner

University Clinic Magdeburg, Magdeburg, Germany

H. Messmann

Klinikum Augsburg, Augsburg, Germany

H.-J. Meyer

Städtisches Klinikum Solingen, Solingen, Germany

C. Röcken

Charité Universitätsmedizin Berlin, Berlin, Germany

C. Schuhmacher

University Hospital Klinikum Rechts der Isar, Munich, Germany

M. Stahl

Kliniken Essen-Mitte, Essen, Germany

M. Stuschke

Essen University Hospital, Essen, Germany 
locally advanced cancers of the stomach or esophagogastric junction $(\geq \mathrm{T} 3 \mathrm{~N}+)$, preferred treatment is preoperative and postoperative chemotherapy. Preoperative radiochemotherapy is an evidence-based alternative for large AEG type I-II tumors ( $\geq \mathrm{T} 3 \mathrm{~N}+$ ). Additionally, some experts recommend treating $\mathrm{T} 2$ tumors with a similar approach, mainly because pretherapeutic staging is often considered to be unreliable.

Conclusions The German S3 guideline represents an upto-date European position with regard to diagnosis, staging, and treatment recommendations for patients with locally advanced esophagogastric cancer. Effects of perioperative chemotherapy versus chemoradiotherapy are still to be investigated for adenocarcinoma of the cardia and the lower esophagus.

Keywords Guidelines · Esophageal cancer · Gastric cancer $\cdot$ Perioperative therapy $\cdot$ Diagnosis

\section{Introduction}

Nationwide clinical guidelines have become more and more indispensable for the definition, implementation and maintenance of healthcare system-specific diagnostic and therapeutic standards [1-6]. These recommendations are increasingly being used in everyday clinical practice. Despite these efforts, some published guidelines have not met high-quality methodological standards (evidence-based plus a formal consensus), being mainly based on expert consensus. Furthermore, large randomized international studies or systematic meta-analyses increasingly define the best world-wide, evidence-based medicine strategies in multidisciplinary oncology therapy, which sometimes conflict with state healthcare system viewpoints.

Apart from many other high incidence and prevalence regions such as Japan or Portugal, more than 20,000 new diagnoses of gastric cancer, including adenocarcinoma of the lower esophagus, were made in Germany in 2008 alone [7]. Therefore, a German guideline on "diagnosis and treatment of clinical manifestations of esophagogastric cancer" was established in 2011, under high-quality, evidence-based data screening plus formal consensus pro-

\footnotetext{
M. Vieth

Klinikum Bayreuth, Bayreuth, Germany

C. Wittekind

Universitätsmedizin Leipzig, Leipzig, Germany

D. Wagner

Center Hospitalier Universitaire Vaudois, Lausanne,

Switzerland
}

cesses ( $\mathrm{S} 3$ process). As other guidelines have also been updated [8,9], this article compares the German recommendations within the framework of recently published studies and other well-defined national guidelines, particularly on diagnosis and treatment of early and locally advanced esophagogastric cancers.

\section{Methods}

In 2008, the German Cancer Society (DKG), the Association of Scientific Medical Societies in Germany (AWMF) and the German Cancer Aid (DKH) decided to support the development of clear evidence-based and healthcare-system-independent guidelines for all fields of oncology. The primary aim was to develop recommendations using only methodologically established evidence-based guidelines or primary evidence, and to achieve an interdisciplinary consensus. The first gastric cancer S3 guideline was published by the German Society of Digestion and Metabolism disease (DGVS) and can be found on the AWMF homepage (www.awmf.org) [7]. The organizing committee invited 108 experts involved in the management of gastric cancer (from 24 medical societies), patient organizations and experts in nutrition and pain. Each medical society selected authors for ten different working groups. The methodological support on selected key questions was provided by the Agency of Quality in Medicine (ÄZQ). To identify evidence and formulate the recommendations, a specific AWMF approved development process was used. Herein, three strategies, including de novo literature research, adaptation of other available guidelines or consensus according to good clinical practice, could be used. After the definition of key words and inclusion/exclusion criteria, working groups conducted specific research using PubMed and the Cochrane Library. The database of the Guidelines International Network (G-I-N) was used to search for international reference guidelines. After establishing the evidence, all working groups discussed and approved their recommendations. Finally, universal voting of the full consensus group (all guideline authors) took place. When statements were difficult to draw conclusions due to limited evidence or disparate expert opinions that could not be answered by the recent guidelines $[1-3,6,8]$, recommendations were stated as good clinical practice (GCP).

Since the diagnosis and treatment of early and locally advanced esophagogastric cancers is an evolving field, the major statements of the German S3 guideline with its grades of evidences and levels of consensus, which already included recent recommendations of Belgium [10] and France [11], were now compared with recently published papers identified by PubMed (01 January 2011-1 August 
2013) and other recent well-defined national guidelines out of G-I-N (NCCN Guidelines ${ }^{\circledR}$ Gastric Cancer in the USA [6,9], Allum et al. [8] for the guideline in the UK, SIGN in Scotland [12]). Levels of evidence of publications were classified according to Oxford criteria [7] (Table 1).

\section{Results}

Primary diagnosis and staging

Full endoscopy provides the highest sensitivity and specificity for the detection of neoplasia in the upper gastrointestinal tract (Table 2). This is consistent across all national and international guidelines. If cancer is suggested, a minimum of eight biopsies should be taken from all suspicious areas. The question of how often and when the patient should undergo re-biopsy or more invasive procedures to determine histology remains unsolved (Supplemental Tables 1 and 2). The NCCN and German S3 guideline made distinctions between early lesions that are potentially curative, and macroscopically large and advanced or symptomatic lesions. For large lesions, especially symptomatic ones, in which tumors could not be detected in repeated biopsies, endoscopic resection or wrinkles using either a combined laparoscopic and endoscopic surgical procedure should be considered [4, 13-15]. Additionally, there is consistency across all national guidelines that a thorough staging is mandatory for decision making, and that it has to take place before endoscopic or surgical resection or neoadjuvant treatment $[8,9,12]$ (Table 3). Here, German and American experts agreed that it is still useful to base therapeutic decisions on the Siewert classification of gastroesophageal junction tumors [16] (Table 4).

For primary staging only, B-mode ultrasonography has a sensitivity of $53-81 \%$ and a specificity of $60-98 \%$ for the detection of liver metastases [17]. The delineation of metastases from primary malignant and benign liver tumors is possible using contrast-enhanced B-mode ultrasonography as opposed to a computed tomography (CT) with an identical accuracy of $>90 \%$. B-mode ultrasonography is also at least equal to CT for the detection of cervical lymph node metastases in adenocarcinomas of the esophagogastric junction (AEG) [18]. In general, CT should be performed as contrast-enhanced examination of the thorax and abdomen and as multi-detector CT with at least a biphasic protocol (native phase and portal venous phase). Further details are described in Supplemental Table 3.

The role of laparoscopy remains unclear [7-9, 12]. Laparoscopy is useful in advanced-stage disease [19], and can be utilized as a last resort for patients where cancer may be suspected, despite negative biopsies and negative endoscopic ultrasonography (EUS) findings. Furthermore, laparoscopy may be helpful for the detection or exclusion of an endoscopically uncertain linitis plastica tumor.

EUS is superior to other tomographies for imaging the esophagogastric wall layers, and is therefore the gold standard for assessing the tumor infiltration depth. This is consistant throughout different national guidelines [7-9, 12]. EUS is also the method of choice in detecting locoregional lymph node metastases, as it has equivalent sensitivity and specificity as other radiological tomographies. However, EUS alone is not reliable enough to exclude lymph node metastases. There is broad European consensus that EUS should be an obligatory component of staging when neoadjuvant therapy is being considered and that limitations of accuracy exist in evaluating the invasion of serosa, impassable stenosis, ulcerated tumors, undifferentiated carcinoma and increased tumor diameters [7-12].

\section{Endoscopic resection}

With regard to careful description of indication and procedure of endoscopic resection (ER), ER is considered sufficient for mucosal gastric carcinoma (T1a) in all European guidelines, as the incidence of lymph node metastatic disease is very low [7-12]. Particularly, the German S3 (Supplemental Table 3) reiterates and enforces the focused knowledge and clear details of the Japanese guideline [20]. If the diagnostic histopathological findings confirm a submucosal carcinoma (T1b) after ER, surgical resection that includes systematic lymphadenectomy has to be performed, because database findings indicate lymph node involvement in up to $20 \%$ of these patients. The earlier established "extended criteria" for ER can only be used in the context of studies, since these need expertise, most likely present in high-volume centers [21-24]. ER of early gastric cancer should be performed as a complete enbloc resection, which allows a complete histological evaluation of the lateral and basal margins. Patients treated with ER should receive endoscopic surveillance with follow-up endoscopy every 3 months in the first year, every 6 months in the second year, and then annually. For local recurrence after ER, early gastric carcinoma can be treated endoscopically, providing that there is only mucosal involvement (rT1aNOM0). Alternatively, a surgical procedure can be selected.

\section{Surgery}

The most relevant prognostic factors for recurrence are tumor location, the depth of local infiltration and locoregional lymph node involvement [25] (Supplemental Table 4). Nodal status assessment includes the preparation 


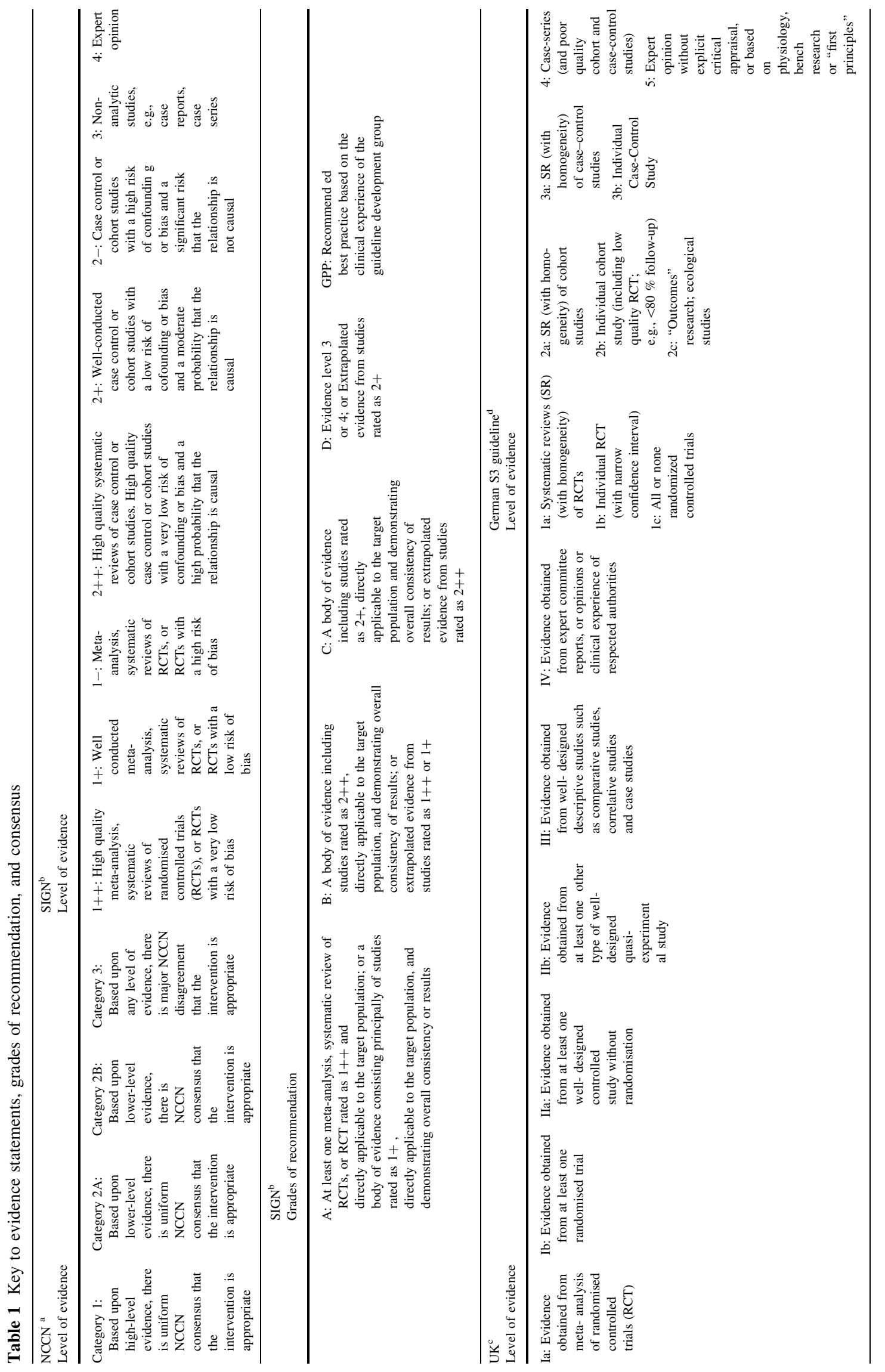


of all lymph nodes and the evaluation of the number of affected lymph nodes in proportion to the number examined. The resection lines should be verified and classified (R0, R1, R2). The primary goal of surgery is to accomplish a complete resection with negative margins ( $\mathrm{R} 0$ resection). This is consistent with other major guidelines on gastric cancer $[8,9,12]$. Furthermore, the presence of distant metastases, vascular invasion and the dissociation of tumor cells in the area of invasion are additional prognostic factors. The dissociation of tumor cells in the area of invasion and vascular invasion have been validated as independent prognostic factors [16, 26, 27]. Vascular invasion is an independent prognostic factor for cardia and distal gastric cancer $[16,26]$.

Proximal safety distances are based on the early works of Hermanek et al. [7, 12]. Diffuse gastric carcinomas occasionally show a proximal discontinuous distribution in the gastric wall. A proximal resection margin of $5-8 \mathrm{~cm}$ in situ (corresponding to $>5 \mathrm{~cm}$ in the fresh preparation) is a safe distance, with a very low probability of tumor detection in the resection margin. For intestinal gastric carcinomas, a discontinuous propagation was not detected. Therefore, a sufficient distance from the proximal resection margin is $4-5 \mathrm{~cm}(2-3 \mathrm{~cm}$ according to the fresh preparation). In the USA, complete resection with adequate margins of $4 \mathrm{~cm}$ or greater is widely considered as a standard goal (whereas the type of resection and the number of lymph node dissections remain controversial) [9]. If these proximal safety distances are maintained, only diffuse carcinomas in the lower third of the stomach can be treated with a subtotal distal gastrectomy. For cancer in the upper third of the stomach and adenocarcinomas of the esophagogastric (AEG) junction type II and III, an expanded gastrectomy with distal esophagectomy is appropriate [7, 12]. For patients with carcinoma of the intestinal type, a distal subtotal gastrectomy may be possible in cancers of the lower third and even for the middle third. For AEG junction of the cardia and AEG type II and III, a distal esophageal resection, as well as a gastrectomy, is necessary. For all patients with T1-T4 tumors, curative surgery should be the aim. Patients with T4b tumors that involve non-resectable structures and those with distant metastases should not be subjected to radical surgery. This is consistent with other major guidelines on gastric cancer $[8,9,12]$.

There are insufficient data for cases of $\mathrm{R} 1$ resection where a second operation was curative. Depending on the location of the previous R1-resection and the functional operability, a re-operation should be attempted with the aim of R0 resection.

Regional lymph nodes prevent a systemic spread of tumor cells for an uncertain length of time. Thus, lymph node status impacts on prognosis, and is essential for the 


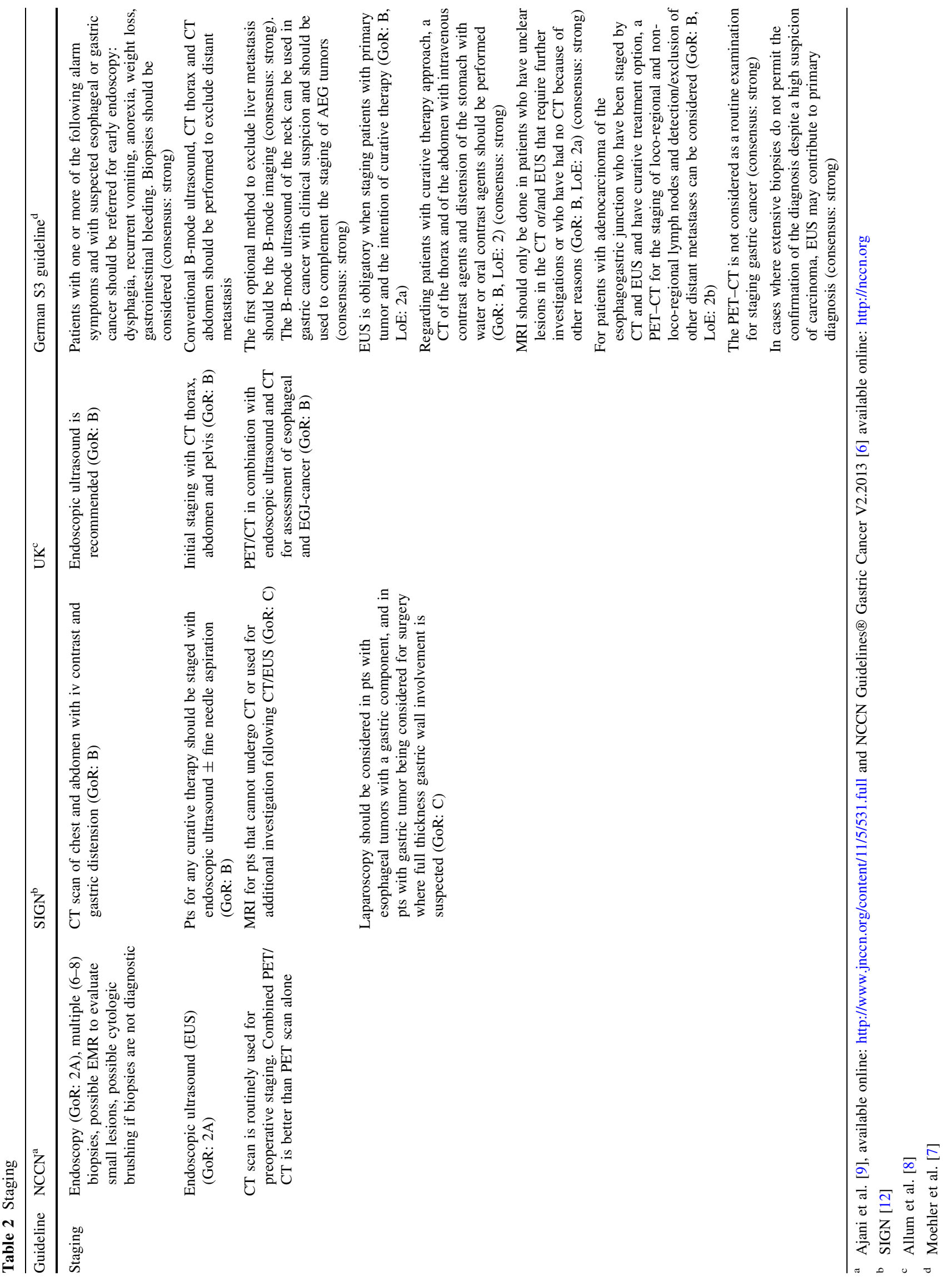


Table 3 Comparison perioperative chemotherapy

\begin{tabular}{|c|c|c|c|c|c|c|}
\hline & \multicolumn{2}{|c|}{ MAGIC $(n=503)$} & \multicolumn{2}{|c|}{$\operatorname{ACCORD}(n=224)$} & \multicolumn{2}{|c|}{ EORTC $(n=114)$} \\
\hline & $\mathrm{S}$ & $\mathrm{CT}+\mathrm{S}$ & $S$ & $\mathrm{CT}+\mathrm{S}$ & S & $\mathrm{CT}+\mathrm{S}$ \\
\hline $\mathrm{R} 0$ resection & $66 \%$ & $69 \%$ & $74 \%$ & $87 \%$ & $67 \%$ & $82 \%$ \\
\hline$p$ value & \multicolumn{2}{|c|}{ n.s. } & \multicolumn{2}{|c|}{0.04} & \multicolumn{2}{|c|}{0.036} \\
\hline $5-y$ OS & $23 \%$ & $36 \%$ & $24 \%$ & $38 \%$ & n.a. & n.a. \\
\hline Hazard ratio & \multicolumn{2}{|c|}{0.75} & \multicolumn{2}{|c|}{0.69} & \multicolumn{2}{|c|}{0.84} \\
\hline Confidence interval & \multicolumn{2}{|c|}{$95 \%$ CI $0.6-0.93$} & \multicolumn{2}{|c|}{$95 \%$ CI $0.5-0.95$} & \multicolumn{2}{|c|}{$95 \%$ CI $0.52-1.35$} \\
\hline$p$ value & \multicolumn{2}{|c|}{0.009} & \multicolumn{2}{|c|}{0.021} & \multicolumn{2}{|c|}{0.466} \\
\hline Post-OP CT completed in & \multicolumn{2}{|c|}{$41.6 \%$} & \multicolumn{2}{|c|}{$50 \%$} & \multicolumn{2}{|c|}{$<50 \%$} \\
\hline \multirow[t]{3}{*}{ Tumor localization } & \multicolumn{2}{|c|}{ EGJ: $11 \%$} & \multicolumn{2}{|c|}{ Lower esophagus and EGJ: $75 \%$} & \multicolumn{2}{|c|}{ EGJ and upper third of stomach: $53 \%$} \\
\hline & \multicolumn{2}{|c|}{ Lower esophagus: $15 \%$} & \multicolumn{2}{|c|}{ Gastric cancer: $25 \%$} & \multicolumn{2}{|c|}{ Middle third of stomach: $26 \%$} \\
\hline & \multicolumn{2}{|c|}{ Gastric cancer: $74 \%$} & & & \multicolumn{2}{|c|}{ Lower third of stomach: $21 \%$} \\
\hline
\end{tabular}

$S$ surgery, $C T$ chemotherapy, n.s. not significant, n.a not available, $O S$ overall survival, EGJ esophagogastric junction

Table 4 Perioperative therapy

\begin{tabular}{|c|c|c|c|c|}
\hline Guideline & $\mathrm{NCCN}^{\mathrm{a}}$ & $\mathrm{SIGN}^{\mathrm{b}}$ & $\mathrm{UK}^{\mathrm{c}}$ & 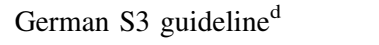 \\
\hline \multirow[t]{3}{*}{$\begin{array}{l}\text { Preoperative } \\
\text { RCTx }\end{array}$} & $\begin{array}{l}\text { Preoperative CRTx is the } \\
\text { preferred approach for } \\
\text { localized EGJ } \\
\text { adenocarcinoma. } \\
\text { Perioperative CTx is an } \\
\text { alternative but less preferred } \\
\text { option }\end{array}$ & & $\begin{array}{l}\text { Definitive treatment of choice } \\
\text { for localized squamous cell } \\
\text { carcinoma of the proximal } \\
\text { esophagus (GoR: A, LoE: } \\
\text { Ia) }\end{array}$ & $\begin{array}{l}\text { In localized adenocarcinoma } \\
\text { of the esophagogastric } \\
\text { junction (stage uT3 and } \\
\text { resectable uT4), either } \\
\text { perioperative chemotherapy } \\
\text { or neoadjuvant RCT should } \\
\text { be performed. Perioperative } \\
\text { chemotherapy: (GoR: A, } \\
\text { LoE: 1b). Neoadjuvant } \\
\text { RCT: (GoR: A LoE: 1a-b, } \\
\text { 1b-2b) }\end{array}$ \\
\hline & $\begin{array}{l}\text { The value of preoperative } \\
\text { RCTx for pts with resectable } \\
\text { gastric cancer remains } \\
\text { uncertain (ongoing } \\
\text { international trial } \\
\text { TOPGEAR). }\end{array}$ & & $\begin{array}{l}\text { Improves long-term survival } \\
\text { over surgery for esophageal } \\
\text { adenocarcinoma (including } \\
\text { type I, II and III) (GoR: A, } \\
\text { LoE: Ia) }\end{array}$ & $\begin{array}{l}\text { Preoperative RCT should not } \\
\text { be performed in gastric } \\
\text { cancer }\end{array}$ \\
\hline & $\begin{array}{l}\text { Induction CTx prior to } \\
\text { preoperative RCTx may be } \\
\text { appropriate in selected pts }\end{array}$ & & & \\
\hline \multirow[t]{2}{*}{$\begin{array}{l}\text { Preoperative } \\
\text { RTx }\end{array}$} & $\begin{array}{l}\text { In general, Siewert I and II } \\
\text { tumors should be managed } \\
\text { with radiation therapy } \\
\text { guidelines applicable to } \\
\text { esophageal cancers. } \\
\text { Depending on the clinical } \\
\text { situation, Siewert III tumors, } \\
\text { may be more appropriately } \\
\text { managed with radiation } \\
\text { therapy guidelines } \\
\text { applicable to either } \\
\text { esophageal or gastric cancer. }\end{array}$ & $\begin{array}{l}\text { Preoperative RTx is not } \\
\text { recommended for pts with } \\
\text { esophageal cancer (GoR: A) }\end{array}$ & $\begin{array}{l}\text { Not recommended for } \\
\text { esophageal squamous cell } \\
\text { carcinoma (GoR: A, } \\
\text { LoE: Ia) }\end{array}$ & $\begin{array}{l}\text { In localized adenocarcinoma } \\
\text { of the esophagogastric } \\
\text { junction (stage uT3 and } \\
\text { resectable uT4), either } \\
\text { perioperative chemotherapy } \\
\text { or neoadjuvant RCT should } \\
\text { be performed. Perioperative } \\
\text { chemotherapy: (GoR: A/B, } \\
\text { LoE: } 1 \mathrm{~b}) \text {. Neoadjuvant } \\
\text { RCT: (GoR: A/B, LoE: 1a- } \\
\text { b, 1b-2b) }\end{array}$ \\
\hline & $\begin{array}{l}\text { Dose: } 45-50,4 \text { Gy (1.8 Gy/ } \\
\text { day) }\end{array}$ & & $\begin{array}{l}\text { Not recommended for } \\
\text { esophageal adenocarcinoma } \\
\text { (GoR: A, LoE: Ia) }\end{array}$ & \\
\hline
\end{tabular}


Table 4 continued

\begin{tabular}{|c|c|c|c|c|}
\hline Guideline & $\mathrm{NCCN}^{\mathrm{a}}$ & $\mathrm{SIGN}^{\mathrm{b}}$ & $\mathrm{UK}^{\mathrm{c}}$ & German S3 guideline $^{\mathrm{d}}$ \\
\hline \multirow[t]{4}{*}{$\begin{array}{l}\text { Perioperative } \\
\text { CTx }\end{array}$} & $\begin{array}{l}\text { Based on results from MAGIC } \\
\text { and FNLCC/FFCD trial: } \\
\text { category } 1 \text { recommendation } \\
\text { after R0 resection for all pts. } \\
\text { with T1b, T2 or higher, any } \\
\mathrm{N} \text { tumor with limited lymph } \\
\text { node dissection (D0 or D1). } \\
\text { However, perioperative CTx } \\
\text { is seen as an alternative to } \\
\text { RCTx }\end{array}$ & $\begin{array}{l}\text { Pts with operable esophageal } \\
\text { cancer, who are treated } \\
\text { surgically, should be } \\
\text { considered for two cycles of } \\
\text { preoperative CTx with } \\
\text { cisplatin and 5-FU or } \\
\text { offered entry into a clinical } \\
\text { trial (GoR: B) }\end{array}$ & $\begin{array}{l}\text { Preoperative CTx with } \\
\text { cisplatin and 5-FU } \\
\text { improves long-term } \\
\text { survival over surgery alone } \\
\text { for esophageal } \\
\text { adenocarcinoma (GoR: A, } \\
\text { LoE: Ia) }\end{array}$ & $\begin{array}{l}\text { In localized adenocarcinoma } \\
\text { of the stomach or } \\
\text { esophagogastric junction } \\
\text { (stage uT2), preoperative } \\
\text { chemotherapy can be } \\
\text { performed and continued } \\
\text { postoperatively (GoR: } 0 \text {, } \\
\text { LoE: } 1 \mathrm{~b} \text { ) }\end{array}$ \\
\hline & \multirow[t]{3}{*}{$\begin{array}{l}\text { Perioperative CTx or } \\
\text { postoperative CRTx is the } \\
\text { preferred approach for } \\
\text { localized gastric cancer }\end{array}$} & $\begin{array}{l}\text { Neoadjuvant use of either } \\
\text { CTx or RTx for pts with } \\
\text { gastric cancer is not } \\
\text { recommended outside } \\
\text { clinical trials (GoR: A) }\end{array}$ & $\begin{array}{l}\text { Perioperative CTx conveys } \\
\text { survival benefit for pts with } \\
\text { esophageal adenocarcinoma } \\
\text { and is the preferred option } \\
\text { for type II and III EGJ- } \\
\text { tumors (GoR: A; Ib) }\end{array}$ & $\begin{array}{l}\text { In localized adenocarcinoma } \\
\text { of the stomach (stage uT3 } \\
\text { and resectable uT4a), } \\
\text { perioperative chemotherapy } \\
\text { should be performed, i.e. be } \\
\text { started preoperatively and } \\
\text { continued postoperatively } \\
\text { (GoR: A/B, LoE: } 1 \mathrm{~b})\end{array}$ \\
\hline & & \multirow[t]{2}{*}{$\begin{array}{l}\text { Intraperitoneal CTx and } \\
\text { immunotherapy for pts with } \\
\text { gastric cancer are not } \\
\text { recommended outside a } \\
\text { clinical trial (GoR: C) }\end{array}$} & \multirow[t]{2}{*}{$\begin{array}{l}\text { Perioperative CTx conveys a } \\
\text { significant survival benefit } \\
\text { for pts with gastric } \\
\text { adenocarcinoma and is } \\
\text { standard of care (GoR: A, } \\
\text { LoE: } \mathrm{Ib} \text { ) }\end{array}$} & $\begin{array}{l}\text { In localized adenocarcinoma } \\
\text { of the esophagogastric } \\
\text { junction (stage uT3 and } \\
\text { resectable uT4), either } \\
\text { perioperative chemotherapy } \\
\text { or neoadjuvant RCT should } \\
\text { be performed. Perioperative } \\
\text { chemotherapy: (GoR: A/B, } \\
\text { LoE: } 1 \text { b). Neoadjuvant } \\
\text { RCT: (GoR: A/B, LoE: 1a- } \\
\text { b, 1b-2b) }\end{array}$ \\
\hline & & & & $\begin{array}{l}\text { Antibodies and "small } \\
\text { molecules" should not be } \\
\text { used for perioperative } \\
\text { therapy (consensus: strong) }\end{array}$ \\
\hline
\end{tabular}

$\overline{\text { a }}$ Ajani et al. [9], available online: http://www.jnccn.org/content/11/5/531.full and NCCN Guidelines® Gastric Cancer V2.2013 [6] available online: http://ncen.org

b SIGN [12]

c Allum et al. [8]

d Moehler et al. [7]

analysis of treatment results [7, 12]. For the $\mathrm{pN}$ status in gastric cancer, a minimum of 16 examined lymph nodes is required for a reliable assessment in Germany [7]. The UK guideline requires at least 15 examined lymph nodes [8]. Compared with D1-LAD, the majority of non-randomized studies showed a prognostic advantage, with lower morbidity and mortality for radical D2-LAD. In the German gastric cancer study, a prognostic advantage of the D2LAD was detected for the Union for International Cancer Control (UICC) stage II and IIIA disease [7, 16]. Two recent prospective observational studies confirm the results of the non-randomized studies of the 1990s [28, 29], and randomized studies from the Netherlands and the UK confirm earlier work that found lower rates of loco-regional recurrences after D2-LAD [30]. In two randomized trials with high proportions of splenectomy/pancreatectomy, a prognostic advantage after D2-LAD could not be detected [30, 31]. In both studies and subsequent multivariate analyses, the combined splenectomy/pancreatectomy was associated with a significant increase in morbidity and mortality, and was evaluated as an independent negative prognostic factor.

On the basis of these results, pancreatic left resection and splenectomy should be avoided. The NCCN guidelines recommend splenectomy only when spleen or hilum is involved [9]. The 10- and 15-year results of the Dutch Gastric Cancer Study showed reduced cancer-related mortality after D2-LAD and lower loco-regional recurrence rates [32-34]. An extension of $L A D$, for example, para-aortic lymph node resection, does not lead to further improvement of prognosis [34]. Based on the results of two randomized trials, a D2 \pm , D3 or D4-LAD is not recommended for gastric cancer. 


\section{Perioperative therapy}

Perioperative chemotherapy in locally advanced gastric and esophagogastric junction tumors

In all recent Western guidelines, there are clear recommendations for perioperative chemotherapy as a "preferred approach" (Scotland SIGN: GoR B [12], UK guideline: GoR: A, LoE: Ib [8], Germany S3: GoR A/B, LoE: Ib [7]) for locally advanced tumors of the stomach and lower esophagus. These recommendations are based on a detailed analysis of the literature (Tables 3, 4; Supplemental Table 5). For the MAGIC study, hazard ratio (HR) for death was significantly lower $(0.75 \%)$ in the chemotherapy group $(95 \% \mathrm{CI}$ $0.6-0.93, p=0.009)$ compared to surgery alone (Table 3). In this trial, three ECF cycles (5-fluorouracil [5-FU], cisplatin, and epirubicin) were given before and after surgery, and there was a significant improvement in OS of 7.4 and $12.5 \%$ after 4 and 5 years compared with surgery alone, respectively. Data on neoadjuvant chemotherapy has been available from at least five randomized trials that included patients with lower esophageal adenocarcinoma [5, 35-39]. In the French ACCORD trial, perioperative cisplatin/infusional 5-FU again conferred a significant benefit after 5 years on DFS (34 vs. $21 \%$, HR 0.68, $p=0.0033$ ) and OS (38 vs. $24 \%$, HR 0.69, $p=0.021$ ) [36]. Several metaanalyses have demonstrated a statistically significant benefit for neoadjuvant chemotherapy [40-42]. The EORTC 40954 trial, which primarily included patients with AEG junction, contributed to the evidence for neoadjuvant chemotherapy [37]. In this trial, cisplatin/5-FU as a PLF regimen was used only preoperatively. However, the study was terminated prematurely due to lack of recruitment. The rate of $\mathrm{R} 0$ resections improved significantly (81.9 vs. $66.7 \%$, $p=0.036$ ), which is important because cure is impossible without R0 resection. Furthermore, progression-free survival was significantly longer in the chemotherapy arm, with a similar median survival time in both arms.

Thus far, in many trials, the proportion of patients with tumors of the esophagus, the esophagogastric junction or the stomach in individual trials was not always clear, and results for these sites have not been reported separately (Table 3). Post-hoc analysis of Medical Research Council trials showed no difference in chemotherapy effectiveness for esophageal, esophagogastric junction and distal gastric tumors [43]; the above meta-analyses were limited in their value because of the inclusion of studies with mixed tumor types. Surgical and pathological quality control was insufficient and not clearly defined [35]. The French trial had heterogeneous inclusion criteria with inclusion of patients with distal esophageal cancer [36].

In recently published trials of neoadjuvant chemotherapy for tumors of the esophagus or esophagogastric junction, patients with predominantly stage II and III disease were included $[35,39]$; one study with negative results also allowed the inclusion of stage I patients [44]. Thus, results from randomized phase III trials for patients with tumors classified as uT2 N0 only have not been available. Furthermore, the pre-therapeutic determination of nodal status is not regarded as a reliable basis for decisionmaking in general, and nodal involvement is only present in about $30-40 \%$ of T2 tumor cases. Also, neoadjuvant and perioperative chemotherapy have not been studied in T2 tumors without nodal involvement. On this basis, the recommendation for neoadjuvant chemotherapy for uT2 tumors was pronounced as a "can-recommendation" with appropriate reluctance (GoR: 0, LoE: 1b, consensus).

Neoadjuvant radiochemotherapy in uT3-4 esophagogastric junction tumors

As supported by nearly all Western guidelines, as shown in Table 5 [6-8, 12], evidence of at least four randomized trials supported neoadjuvant radiochemotherapy (RCT) vs. resection alone in localized esophageal cancer [45-48]. Two of these studies [45, 48] showed a statistically significant advantage (lower mortality) for neoadjuvant RCT. One further study showed a nonsignificant trend in favor of neoadjuvant RCT. Several previous meta-analyses [49-52] confirmed these results for adenocarcinoma. The metaanalysis by Gebski demonstrated a statistically significant survival benefit for both neoadjuvant chemotherapy and neoadjuvant RCT [40]. The clinical value of preoperative radiotherapy (RT) alone versus surgery alone was also evaluated in a randomized study of 370 patients; a survival advantage of $10 \%$ after 5 years and $7 \%$ after 10 years $(p=0.009)$ was observed for $\mathrm{RT}$, with no increase in perioperative mortality [53].

Preoperative RCT vs. preoperative chemotherapy alone was addressed in a recent randomized trial in locally advanced AEG [54]. When closed prematurely due to low recruitment, this trial showed a nonsignificant overall survival trend for RCT, with no significant difference in treatment-related mortality between the trial arms. Preoperative RCT (Cross trial) also resulted in a significantly improved histological response rate, and patients with a histological tumor response had a significantly better longterm prognosis [55].

\section{Adjuvant strategies}

In contrast to Asian and North American, primary adjuvant therapy concepts are not regularly standards in Europe (Tables 4, 5). Despite repeated meta-analyses and positive Asian Phase III studies for chemotherapy alone (e.g., with Platin/S-1) and despite established adjuvant chemoradiation 
protocols for North America, no clear recommendations for adjuvant therapy solely are available in Europe [7, 8, 12].

Overall, survival improvement by perioperative therapy seemed to be larger than by adjuvant therapy (13 vs. $5.8 \%)$. The hazard ratio for OS was $0.96(95 \% \mathrm{CI}$ 0.83-1.12) in "Western" studies, and 0.58 (95\% CI 0.44-0.76) in Asian studies. In recent randomized trials, the results were negative in Europe, while individual studies in Asia showed a significant survival benefit for adjuvant chemotherapy. The recently published meta-analysis by the GASTRIC Group on the basis of individual patient data with 3,838 patients from 17 studies, comprised two-thirds of all completed phase III trials with a median follow-up of more than 7 years. This large analysis had an advantage for adjuvant chemotherapy, with an HR for OS of 0.82 (95\% CI $0.76-0.90, p<0.001)$, corresponding to an absolute OS improvement at 5 years of $5.8 \%$. This can be explained by weaker postoperative general conditions of many patients, allowing fewer feasible therapies [35, 36].

If, however, no preoperative therapy procedures have been initiated in patients with inadequate staging or emergency surgery, adjuvant chemotherapy may be considered according to the present evidence, and offered to patients with primary locally advanced tumor stages (especially with positive LN status). With a lack of alternative therapies for high-risk patients, the German AIO established an improved adjuvant RCTX therapy with capecitabine/oxaliplatin and irradiation [56]. Due to the expected high side effects, however, this should be considered only after extensive discussion and consideration of the side effects, compared to the aim of therapy.

\section{Discussion}

During recent years, significant progress has been made in the diagnostic and therapeutic measures of early and locally advanced gastric cancers, including adenocarcinoma of the lower esophagus. In contrast to other current European guidelines, the German evidence and consensus-based S3 guideline particularly favors the eradication of $\mathrm{H}$. pylori in risk populations, as well as the benefit of qualified staging procedures such as CT scans and EUS. Although PET-CT is not considered as a routine examination for staging of gastric cancer [7, 9, 12], Italian and NCCN colleagues emphasize that-despite its drawbacks-PET/CT has a higher positive predictive value for lymph node metastasis compared to CT scan, and may have a role in monitoring response to neoadjuvant chemotherapy (NCCN: GoR; B [6]; Manzoni, EUNE gastric cancer workshop in Cologne 2012). Manzoni referred to a prospective study of 113 patients that used FDG-PET/CT, identifying occult metastatic lesions in approximately $10 \%$ of patients with locally advanced gastric cancer.

The evidence for perioperative therapy has changed over the past years. Since significant survival advantages were reached in recent trials, perioperative chemotherapy for locally advanced gastric tumors and the neoadjuvant radiochemotherapy for esophagogastric junction adenocarcinomas are now intensively supported in the recent European guidelines [11] by high evidence levels and grade of recommendations. In contrast to other European guidelines, the German experts acknowledged the benefit of perioperative chemotherapy for locally advanced tumors [7]. However, full consensus could not be achieved regarding a final recommendation. At the time, when the German S3 guideline was finally completed in 2010, only the phase III MAGIC study was fully reported [35]. Important deficiencies in the study included: heterogeneous tumor locations, lack of surgical and pathological quality controls, and endoscopic staging and imprecise data on the extent of resection and the histopathological work-up. Only $30 \%$ of patients had pT2 tumors, and the vast majority of patients had advanced-stage, imprecisely defined tumors. Similar data were seen in the smaller randomized ACCORD trial of 224 patients, with only $25 \%$ being gastric carcinoma patients [36]. Deficiencies of this study were again the lack of clear surgical and pathological quality controls. Similarly, only $50 \%$ of patients received postoperative chemotherapy [35].

In 2009, a new clinical guideline for gastric cancer was released in the Netherlands. In a retrospective analysis, a total of 2,511 patients with primary adenocarcinoma of the stomach were included to investigate the impact of the new guideline. Results show that preoperative chemotherapy was given in $45 \%$ of patients, and $25 \%$ of resections were noncurative. Furthermore, the resection rate was $41 \%$ and 30-day mortality was $5.7 \%$ [57]. Also in 2009, a similar retrospective audit was conducted in Norway, following recommendations for a perioperative chemotherapy based on National Guidelines. In total, 336 patients were operated on for gastric cancer, and $144(43 \%)$ received preoperative chemotherapy. Ninety-two $(54 \%)$ of the patients started postoperative cycles and $68(40 \%)$ completed all cycles. Surgical morbidity and mortality were 26 and $\leq 2 \%$, respectively [58].

Overall and thus far, the perioperative strategy has never been thoroughly compared with adjuvant protocols. Currently, both strategies are also being investigated prospectively in the CRITICS trial [59]. Additionally, a comparative French multicenter study suggested a worse outcome for patients with a signet ring cell type of gastric carcinoma after perioperative chemotherapy versus surgery [60]. Therefore, the Prodice-FFCD group started a randomized controlled trial of perioperative versus adjuvant therapy in these subtype patients [61]. In esophageal 
Table 5 Postoperative therapy

\begin{tabular}{ll}
\hline Guideline & NCCN $^{\mathrm{a}}$ \\
\hline $\begin{array}{l}\text { Postoperative } \\
\text { CRTx }\end{array}$ & $\begin{array}{l}\text { As a result of INT-0116 trial, } \\
\text { postoperative RCTx is standard } \\
\text { of care in pts with completely } \\
\text { resected gastric cancer who } \\
\text { have not received preoperative } \\
\text { therapy. It is also the preferred } \\
\text { option after complete gastric } \\
\text { resection in T3-T4 and node- } \\
\text { positive T1-T2 (GoR: } 1)\end{array}$
\end{tabular}

INT-0116 Trial: only $64 \%$ of pts completed treatment

T2 N0: Observation or postoperative CRTx only for pts with high-risk features (poorly differentiated or higher-grade cancer, lamphovascular invasion, neural invasion, age $<50$ years) and $\mathrm{R} 0$ resection

After R1 or R2: postoperative CRTx is a treatment option, especially for pts who have not received preoperative CRTx

Postoperative CRTx is the preferred option for pts undergoing less than a D2 lymph node dissection

Postoperative Results from ACTS GC trial and CTx CLASSIC trial support the use of postoperative CTx after curative surgery with D2 lymph node dissection in pts with resectable gastric cancer

Postoperative CTx is offered to all pts with $\mathrm{T} 1$ or higher $\rightarrow$ significantly improves OS and RFS in pts with T3-T4, N0 and any T node-positive tumors

\begin{tabular}{|c|c|c|}
\hline $\mathrm{SIGN}^{\mathrm{b}}$ & $\mathrm{UK}^{\mathrm{c}}$ & ${\text { German S3 } \text { guideline }^{\mathrm{d}}}$ \\
\hline $\begin{array}{l}\text { Postoperative adjuvant } \\
\text { CRTx is not recommended } \\
\text { for pts with esophageal } \\
\text { cancer (GoR: GPP) }\end{array}$ & $\begin{array}{l}\text { Improves survival for pts } \\
\text { with gastric } \\
\text { adenocarcinoma and is } \\
\text { standard of care in the } \\
\text { USA; it should be } \\
\text { considered in pts at high } \\
\text { risk of recurrence } \\
\text { (suboptimal debulking) } \\
\text { who have not received } \\
\text { neoadjuvant therapy } \\
\text { (GoR: A, LoE: Ib) }\end{array}$ & $\begin{array}{l}\text { After primary R0 resection } \\
\text { (without preoperative } \\
\text { chemotherapy) for locally } \\
\text { advanced gastric cancer, } \\
\text { an adjuvant chemotherapy } \\
\text { should not be performed } \\
\text { (GoR: B, LoE: 1a, } \\
\text { Consensus). Dissenting } \\
\text { opinion of DGHO: } \\
\text { Adjuvant chemotherapy } \\
\text { may be considered and } \\
\text { offered to patients with } \\
\text { locally advanced gastric } \\
\text { cancer (especially in cases } \\
\text { with positive lymph node) } \\
\text { when neoadjuvant therapy } \\
\text { has not been initiated due } \\
\text { to inadequate staging }\end{array}$ \\
\hline
\end{tabular}

Postoperative CRTx for pts with gastric cancer is not recommended outside a clinical trial (GoR: GPP)

Postoperative adjuvant CTx is not recommended for pts with esophageal cancer (GoR: A)

Postoperative CTx for pts with gastric cancer is not recommended outside a clinical trial (GoR: B)
Adjuvant CTx for pts with gastric adenocarcinoma is not standard of care, but has survival benefits in non-western populations and should be considered in pts at high risk of recurrence who have not received neoadjuvant therapy (GoR: A, LoE: Ia)

Intraperitoneal CTx for pts with gastric adenocarcinoma remains investigational (GoR: B)
In localized adenocarcinoma of the stomach or esophagogastric junction (stage uT2), preoperative chemotherapy can be performed and continued postoperatively (GoR: 0, LoE: 1b)

In localized adenocarcinoma of the stomach (stage uT3 and resectable uT4a), perioperative chemotherapy should be performed, i.e., be started preoperatively and continued postoperatively (GoR: A/B, LoE: 1b) 
Table 5 continued

\begin{tabular}{|c|c|c|c|c|}
\hline Guideline & $\mathrm{NCCN}^{\mathrm{a}}$ & $\mathrm{SIGN}^{\mathrm{b}}$ & $\mathrm{UK}^{\mathrm{c}}$ & 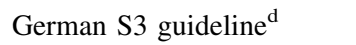 \\
\hline & $\begin{array}{l}\text { Effectiveness in pts with } \mathrm{T} 2 \mathrm{~N} 0 \\
\text { remains unclear }\end{array}$ & & & $\begin{array}{l}\text { In localized adenocarcinoma } \\
\text { of the esophagogastric } \\
\text { junction (stage uT3 and } \\
\text { resectable uT4), either } \\
\text { perioperative } \\
\text { chemotherapy or } \\
\text { neoadjuvant RCT should } \\
\text { be performed. } \\
\text { Perioperative } \\
\text { Chemotherapy: (GoR: } \\
\text { A/B, LoE: 1b). } \\
\text { Neoadjuvant RCT: (GoR: } \\
\text { A/B, LoE: 1a-b, 1b-2b) }\end{array}$ \\
\hline & \multicolumn{4}{|l|}{$\begin{array}{l}\text { Postoperative CTx is an option } \\
\text { for pts with T3-T4 and node- } \\
\text { positive T1-T2 tumors after R0 } \\
\text { resection and a modified D2 } \\
\text { lymph node dissection }\end{array}$} \\
\hline & \multicolumn{4}{|l|}{$\begin{array}{l}\text { No further treatment is necessary } \\
\text { for pts with Tis and T1, N0 } \\
\text { tumors if R0 resection }\end{array}$} \\
\hline & $\begin{array}{l}\text { Not recommended for undergoing } \\
\text { less than a D2 lymph node } \\
\text { dissection (in this case, } \\
\text { postoperative RCTx is the } \\
\text { preferred option, GoR: } 1 \text { ) }\end{array}$ & & & \\
\hline $\begin{array}{l}\text { Perioperative } \\
\text { nutritional } \\
\text { status }\end{array}$ & $\begin{array}{l}\text { B12, iron, and calcium level } \\
\text { should be closely monitored, } \\
\text { especially for postoperative pts. } \\
\text { Feeding jejunostomies may be } \\
\text { placed if clinically indicated }\end{array}$ & $\begin{array}{l}\text { Pts undergoing surgery for } \\
\text { esophageal or gastric } \\
\text { cancer who are identified } \\
\text { as being at high nutritional } \\
\text { risk should be considered } \\
\text { for preoperative nutritional } \\
\text { support (GoR: B) }\end{array}$ & $\begin{array}{l}\text { Pts who are identified as } \\
\text { malnourished prior to } \\
\text { surgery should be } \\
\text { considered for } \\
\text { preoperative nutritional } \\
\text { support for } 10-14 \text { days }\end{array}$ & $\begin{array}{l}\text { Nutritional support should } \\
\text { be carried out regularly } \\
\text { when normal food intake } \\
\text { in pts is insufficient to } \\
\text { counteract a limitation in } \\
\text { prognosis due to } \\
\text { malnutrition (consensus: } \\
\text { strong) }\end{array}$ \\
\hline
\end{tabular}

a Ajani et al. [9], available online: http://www.jnccn.org/content/11/5/531.full and NCCN Guidelines® Gastric Cancer V2.2013 [6] available online: http://nccn.org

b SIGN [12]

c Allum et al. [8]

d Moehler et al. [7]

cancer, a more detailed analysis of postoperative mortality of preoperative RCT showed increased mortality after RCT and resection only for patients with squamous cell carcinoma [62, 63], whereas studies that predominantly included patients with adenocarcinoma had no increase or reduction in mortality $[46-48,55]$. In contrast, the metaanalysis by Fiorica showed that RCT in patients with adenocarcinoma increased post-operative mortality (HR 2.88 , 95\% CI 0.53-15) [49]. However, this was only observed in a study conducted in 1996 that used a form of radiotherapy that is now obsolete and also had other limitations [45]. The equivalent recommendation for chemotherapy or RCT in the preoperative phase was also justified on the basis of toxicity [55]. In a recent review, Crehange recommended primarily preoperative chemotherapy for patients with AEG II and III [42], whereas Renellenfitsch and colleagues clearly supported RCT in the lower esophagus in a recent meta-analysis [64].

In summary, the first German evidence-based and expert consensus guideline clearly defined molecular markers, diagnosis and staging, as well as particularly endoscopic and perioperative treatment recommendations, for locallyadvanced esophagogastric cancers. Since new antibodies and "small molecules" have not yet shown any benefit for perioperative therapy, further innovative trials are needed to improve the outcome in this growing patient population. Thus, as this guideline has been broadly developed by evidence-based medicine techniques and integrates the most recent study results in a consensus-based manner, it represents an up-to-date approach for the diagnosis, 
staging, and treatment suggestions for patients with esophagogastric cancers for other countries as well.

\section{References}

1. Ajani JA, et al. Esophageal and esophagogastric junction cancers. J Natl Compr Canc Netw. 2011;9(8):830-87.

2. Okines A, et al. Gastric cancer: ESMO clinical practice guidelines for diagnosis, treatment and follow-up. Ann Oncol. 2010;21(Suppl 5):v50-4.

3. Van Cutsem E, et al. The diagnosis and management of gastric cancer: expert discussion and recommendations from the 12th ESMO/World Congress on Gastrointestinal Cancer, Barcelona, 2010. Ann Oncol. 2011;22(Suppl 5):v1-9.

4. Japanese Gastric Cancer Association. Japanese gastric cancer treatment guidelines 2010 (ver. 3). Gastric Cancer. 2011;14(2):113-23.

5. Popiela T. Polish Gastric Cancer Study Project; success or failure? Nowotwory. 2011;61(6):91e-3e.

6. NCCN Guidelines ${ }^{\circledR}$ : clinical practice guidelines in oncology: esophageal and esophagogastric junction cancers V2.2013. http:// nccn.org.

7. Moehler M, et al. S3-Leitlinie "Magenkarzinom"-Diagnostik und Therapie der Adenokarzinome des Magens und ösophagogastralen Übergangs (AWMF-Regist.-Nr. 032-009-OL). Z Gastroenterol. 2011;49:461-531.

8. Allum WH, et al. Guidelines for the management of oesophageal and gastric cancer. Gut. 2011;60(11):1449-72.

9. Ajani JA, et al. Gastric cancer, version 2.2013: featured updates to the NCCN guidelines. J Natl Compr Canc Netw. 2013;11(5):531-46.

10. Peeters $M$, et al. Een nationale praktijkrichtlijn voor de aanpak van slokdarm - en maagkanker. Federaal Kenniscentrum voor de Gezondheidszorg (KCE), Brussel KCE reports. 2008; p. 75.

11. Ychou $\mathrm{M}$, et al. Recommandations pour la pratique clinique: standards, options et recommandations 2003 pour la prise en charge des patients atteints d' adénocarcinomes de l'estomac. 2004. Féderation nationale des centres de lutte contre le cancer.

12. SIGN: Scottish Intercollegiate Guidelines Network. Management of oesophageal and gastric cancer. 2006. http://www.sign.ac.uk/ pdf/sign 87.pdf

13. Yalamarthi $\mathrm{S}$, et al. Missed diagnoses in patients with upper gastrointestinal cancers. Endoscopy. 2004;36:874-9.

14. Voutilainen ME, Juhola MT. Evaluation of the diagnostic accuracy of gastroscopy to detect gastric tumours: clinicopathological features and prognosis of patients with gastric cancer missed on endoscopy. Eur J Gastroenterol Hepatol. 2005;17:1345-9.

15. Amin A, et al. Gastric adenocarcinoma missed at endoscopy. J R Coll Surg Edinb. 2002;47:681-4.

16. Siewert JR, et al. Relevant prognostic factors in gastric cancer: ten-year results of the German Gastric Cancer Study. Ann Surg. 1998;228:449-61.

17. Oldenburg A, Albrecht T. Baseline and contrast-enhanced ultrasound of the liver in tumor patients. Ultraschall Med. 2008;29:488-98.

18. van Vliet EP, et al. Ultrasound, computed tomography, or the combination for the detection of supraclavicular lymph nodes in patients with esophageal or gastric cardia cancer: a comparative study. J Surg Oncol. 2007;96:200-6.

19. Power DG, et al. Endoscopic ultrasound can improve the selection for laparoscopy in patients with localized gastric cancer. J Am Coll Surg. 2009;208:173-8.

20. Sano T, Aiko T. New Japanese classifications and treatment guidelines for gastric cancer: revision concepts and major revised points. Gastric Cancer. 2011;14(2):97-100.
21. Soetikno R, et al. Endoscopic mucosal resection for early cancers of the upper gastrointestinal tract. J Clin Oncol. 2005;23:4490-8.

22. Sanomura Y, et al. Clinical validity of endoscopic submucosal dissection for submucosal invasive gastric cancer: a single-center study. Gastric Cancer. 2012;15(1):97-105.

23. Tanaka N, et al. Trends in characteristics of surgically treated early gastric cancer patients after the introduction of gastric cancer treatment guidelines in Japan. Gastric Cancer. 2010;13(2):74-7

24. Hirasawa T, et al. Lymph node metastasis from undifferentiatedtype mucosal gastric cancer satisfying the expanded criteria for endoscopic resection based on routine histological examination. Gastric Cancer. 2010;13(4):267-70.

25. Lorenzen $S$, et al. Prediction of response and prognosis by a score including only pretherapeutic parameters in 410 neoadjuvant treated gastric cancer patients. Ann Surg Oncol. 2012;19(7):2119-27.

26. Shiraishi N, et al. Multivariate prognostic study on large gastric cancer. J Surg Oncol. 2007;96:14-8.

27. Nitti D, et al. Recent advances in conventional and molecular prognostic factors for gastric carcinoma. Surg Oncol Clin N Am. 2008; 17:467-83, vii.

28. Edwards P, et al. Prospective comparison of D1 vs modified D2 gastrectomy for carcinoma. Br J Cancer. 2004;90:1888-92.

29. Degiuli M, et al. Survival results of a multicentre phase II study to evaluate D2 gastrectomy for gastric cancer. $\mathrm{Br} \mathrm{J}$ Cancer. 2004;90:1727-32.

30. Bonenkamp JJ, et al. Extended lymph-node dissection for gastric cancer. N Engl J Med. 1999;340(12):908-14.

31. Cuschieri A, et al. Patient survival after D1 and D2 resections for gastric cancer: long-term results of the MRC randomized surgical trial. Surgical Co-operative Group. $\mathrm{Br}$ J Cancer. 1999; 79(9-10):1522-30.

32. Hartgrink HH, et al. Extended lymph node dissection for gastric cancer: who may benefit? Final results of the randomized Dutch gastric cancer group trial. J Clin Oncol. 2004;22(11):2069-77.

33. Hartgrink HH, van de Velde CJ. Status of extended lymph node dissection: locoregional control is the only way to survive gastric cancer. J Surg Oncol. 2005;90(3):153-65.

34. Songun I, et al. Surgical treatment of gastric cancer: 15-year follow-up results of the randomised nationwide Dutch D1D2 trial. Lancet Oncol. 2010;11(5):439-49.

35. Cunningham D, et al. Perioperative chemotherapy versus surgery alone for resectable gastroesophageal cancer. N Engl J Med. 2006;355:11-20.

36. Boige $\mathrm{V}$, et al. Final results of a randomized trial comparing preoperative 5-fluorouracil $(\mathrm{F}) /$ cisplatin $(\mathrm{P})$ to surgery alone in adenocarcinoma of stomach and lower esophagus. J Clin Oncol. 2007; $25: 18 \mathrm{~S}$

37. Schuhmacher C, et al. Neoadjuvant chemotherapy compared with surgery alone for locally advanced cancer of the stomach and cardia: European Organisation for Research and Treatment of Cancer randomized trial 40954. J Clin Oncol. 2010;28(35):5210-8.

38. Kelsen DP, et al. Long-term results of RTOG trial 8911 (USA Intergroup 113): a random assignment trial comparison of chemotherapy followed by surgery compared with surgery alone for esophageal cancer. J Clin Oncol. 2007;25(24):3719-25.

39. Allum W, et al. Long-term results of a randomized trial of surgery with or without preoperative chemotherapy in esophageal cancer. J Clin Oncol. 2009;27(30):5062-7.

40. Gebski V, et al. Survival benefits from neoadjuvant chemoradiotherapy or chemotherapy in oesophageal carcinoma: a metaanalysis. Lancet Oncol. 2007;8(3):226-34.

41. Urschel J, Vasan H, Blewett C. A meta-analysis of randomized controlled trials that compared neoadjuvant chemotherapy and surgery to surgery alone for resectable esophageal cancer. Am J Surg. 2002;183(2):274-8. 
42. Crehange G, et al. Resectable adenocarcinoma of the oesophagogastric junction care: which perioperative treatment? Cancer Radiother. 2008;12(5):365-73.

43. Okines A, et al. Meta-analysis of the REAL-2 and ML17032 trials: evaluating capecitabine-based combination chemotherapy and infused 5-fluorouracil-based combination chemotherapy for the treatment of advanced oesophago-gastric cancer. Ann Oncol. 2009;20(9):1529-34.

44. Kelsen D, et al. Chemotherapy followed by surgery compared with surgery alone for localized esophageal cancer. N Engl J Med. 1998;339(27):1979-84.

45. Walsh T, et al. A comparison of multimodal therapy and surgery for esophageal adenocarcinoma. N Engl J Med. 1996;335(7): 462-7.

46. Urba $S$, et al. Randomized trial of preoperative chemoradiation versus surgery alone in patients with locoregional esophageal carcinoma. J Clin Oncol. 2001;19(2):305-13.

47. Burmeister B, et al. Surgery alone versus chemoradiotherapy followed by surgery for resectable cancer of the oesophagus: a randomised controlled phase III trial. Lancet Oncol. 2005;6(9): 656-68.

48. Tepper J, et al. Phase III trial of trimodality therapy with cisplatin, fluorouracil, radiotherapy, and surgery compared with surgery alone for esophageal cancer: CALGB 9781. J Clin Oncol. 2008;26(7):1086-92.

49. Fiorica F, et al. Preoperative chemoradiotherapy for oesophageal cancer: a systematic review and meta-analysis Gut. 2004;53(7): 925-30.

50. Geh J, et al. Systematic overview of preoperative (neoadjuvant) chemoradiotherapy trials in oesophageal cancer: evidence of a radiation and chemotherapy dose response. Radiother Oncol. 2006;78(3):236-44.

51. Malthaner R, et al. Neoadjuvant or adjuvant therapy for resectable esophageal cancer: a systematic review and meta-analysis. BMC Med. 2004;2(35). http://www.ncbi.nlm.nih.gov/pmc/arti cles/PMC529457/pdf/1741-7015-2-35.pdf.

52. Urschel J, Vasan H. A meta-analysis of randomized controlled trials that compared neoadjuvant chemoradiation and surgery to surgery alone for resectable esophageal cancer Am J Surg. 2003;185(6):538-43.

53. Zhang Z, et al. Randomized clinical trial on the combination of preoperative irradiation and surgery in the treatment of adenocarcinoma of gastric cardia (AGC)-report on 370 patients. Int J Radiat Oncol Biol Phys. 1998;42(5):929-34.
54. Stahl M, et al. Phase III comparison of preoperative chemotherapy compared with chemoradiotherapy in patients with locally advanced adenocarcinoma of the esophagogastric junction. J Clin Oncol. 2009;27(6):851-6.

55. van Hagen $P$, et al. Preoperative chemoradiotherapy for esophageal or junctional cancer. N Engl J Med. 366(22):2074-84.

56. Hofheinz RD, et al. Oxaliplatin and capecitabine-based chemoradiotherapy for gastric cancer-an extended phase I MARGIT and AIO trial. Int J Radiat Oncol Biol Phys. 2009;73(1):142-7.

57. Ho VK, Damhuis RA, Hartgrink HH. Adherence to national guidelines for gastric cancer in the Netherlands: a retrospective population-based audit. Int J Cancer. 2013;132(5):1156-61.

58. Holmebakk T, Frykholm G, Viste A. Introducing national guidelines on perioperative chemotherapy for gastric cancer in Norway: a retrospective audit. Eur J Surg Oncol. 2010;36(7): 610-6.

59. Dikken JL, et al. Neo-adjuvant chemotherapy followed by surgery and chemotherapy or by surgery and chemoradiotherapy for patients with resectable gastric cancer (CRITICS). BMC Cancer. 2011;11:329.

60. Messager M, et al. The impact of perioperative chemotherapy on survival in patients with gastric signet ring cell adenocarcinoma: a multicenter comparative study. Ann Surg. 2011;254(5):684-93 (discussion 693).

61. Piessen G, et al. Phase II/III multicentre randomised controlled trial evaluating a strategy of primary surgery and adjuvant chemotherapy versus peri-operative chemotherapy for resectable gastric signet ring cell adenocarcinomas-PRODIGE 19FFCD1103-ADCI002. BMC Cancer. 2013;13:281.

62. Bosset J, et al. Chemoradiotherapy followed by surgery compared with surgery alone in squamous-cell cancer of the esophagus. N Engl J Med. 1997;337(3):161-7.

63. Nygaard K, et al. Pre-operative radiotherapy prolongs survival in operable esophageal carcinoma: a randomized, multicenter study of pre-operative radiotherapy and chemotherapy. The second Scandinavian trial in esophageal cancer. World J Surg. 1992;16(6):1104-9.

64. Ronellenfitsch U, et al. Perioperative chemo(radio)therapy versus primary surgery for resectable adenocarcinoma of the stomach, gastroesophageal junction, and lower esophagus. Cochrane Database Syst Rev. 2013;5:Cd008107. 